\title{
A Research on Green Technology Innovation and Energy Development in China*
}

\author{
Yaning Zhang \\ Northeast Electric Power University \\ Jilin, China 132012
}

\author{
Ruiting Fan \\ Northeast Electric Power University \\ Jilin, China 132012
}

\author{
Changlin Ji* \\ Northeast Electric Power University \\ Jilin, China 132012 \\ *Corresponding Author
}

\begin{abstract}
The paper talked the global pattern of green and low-carbon energy in China. China's economy has entered a stage of high quality development. It should determine the status and function of electric power in building clean and lowcarbon, safe and efficient energy system. Based on the longterm research in the field of energy and electricity, the wisdom of experts from all cycle of life is discussed. Based on the profound adjustment of the new pattern of energy medium and long-term development direction, the source - net - load - store coordination and other new technology, new theory become modern analysis and decision to China's energy and power to the transformation of the development trends in $\mathbf{2 0 5 0 .}$
\end{abstract}

Keywords-green technology innovation; energy development; low-carbon energy

\section{INTRODUCION}

\section{A. Background}

The energy sector is surging in 2016. In the first year of the 13th five-year plan, the optimization and implementation protocols were launched, and the energy supply side structural reform, focusing on production capacity and short board, was pressing ahead, and the energy revolution was steadily promoted.

Over the past year, the coal production capacity targets have been successfully completed, the reform of the power system has been comprehensively promoted, and the series of special plans for the power sector have been announced and implemented. In which the 13th five-year plan for energy development was approved. A series of energy development path points to a future low-carbon clean, safe and efficient system of modern energy [1].

By the end of 2016, China's power generation capacity of

*The paper is the initial results of Soft science project of Jilin provincial science and Technology Department, Research on the realization mechanism and path of Jilin electricity consumption side reform under the dual goal (20180418134FG), Jilin Social Science Fund Project, Research on the influence factors and low carbon development of Jilin's energy consumption structure change(2017BS19). over 6,000 kilowatt power plants reached 1.57 billion kw.

\section{B. Energy Development Situation}

The main contradiction of China's current energy development is the lack of coordination between the energy system dominated by fossil energy and its extensive development mode, ecological civilization construction and economic high quality development. The way of energy development needs to change $\mathrm{e}^{[2]}$. The current economic situation should optimize the energy structure, and the government will transform the growth momentum to meet the people's commodity demand.

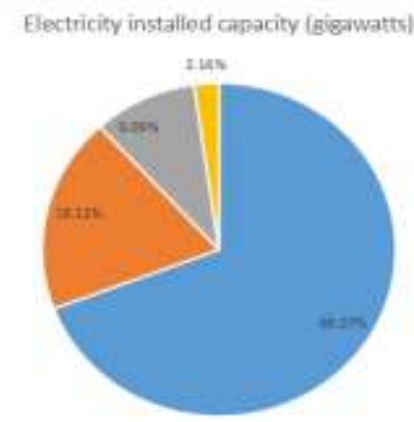

Fig. 1. Electricity installed capacity (gigawatts)

Good ecological environment has become the indispensable part of people's life, but the resources and environmental pressure brought by China's energy utilization is still huge. China proposes to carry out air pollution prevention and control action to recall the blue sky. By 2020, coal will account for less than $58 \%$ of total energy consumption, and the proportion of electric coal in coal consumption will increase to $55 \%$, the proportion of natural gas consumption will increase to about $10 \%$ [3].

Energy security is an overall and strategic issue that concerns the development of national economic society and 
the fundamental interests of the people. China schedules to maintain its energy self-sufficiency capacity at more than 80 percent by 2020, and maintain its energy self-sufficiency at a higher level by 2030 .

Energy consumption levels are still high. Our country proposes that the energy consumption per unit of GDP in 2020 will be $15 \%$ lower than that of 2015 , the world average level in 2030, and the world's advanced level in 2050[4]. The total energy consumption in 2020 and 2030 will be controlled within 5 billion and 6 billion tons of standard coal. Then the total energy consumption will be basically stable by 2050 .

\section{Current Situation of Electric Power Development}

The overall transformation of the energy system means that electricity will play an increasingly important role. The power system has also undergone profound changes in the third energy transition period, providing a steady flow of power system to lead the transformation of energy system.

Before 2050, the power supply will remain fast growing. Under the situation of conventional transformation and electrification acceleration, the installed capacity in 2030 reached 2.87 billion and 3.63 billion kilowatts respectively. The incremental part is mainly clean energy, and the power generation structure is gradually optimized[5]. The proportion of clean energy installed is $54 \%$ to $60 \%$ in 2030 and $79 \%$ to $82 \%$ in 2050 .

Onshore wind power and photovoltaic power generation will be the fastest growing power supply in the future. Coal power will continue to play an important role after the transformation of the role. All kinds of power supply show coordinated development trend. The rapid growth of onshore wind power and photovoltaic power generation will become the main body of power supply in China after 2040.The flexible power supply of gas, electricity, water and heat will play an important role[6]. In the case of high new energy permeability, the wind power will also participate in the adjustment of the peak in the form of reasonable abandoning wind and light, so as to promote the optimal operation of the power system.

\section{ENERGY TRANSFORMATION PATH AND COST INVESTIGATION}

\section{A. Conventional Transformation Scenario}

The enforcement of various types of transformation measures is relatively balanced. Conventional energy-using technology efficiency speed gradually slow, electrification level rising steadily. The coal consumption reduced and the terminal energy consumption structure upgrade steadily. The development of new energy is becoming more and more mature, and the coordinated development of the power system "source-net-hold-storage" has been gradually formed[7].

\section{B. Electrification Acceleration Scenario}

The electrification level grow faster: electric boiler, intelligent household, as well as electric cars and other technology to speed up the popularization and application, the whole society electrification level continues to rise faster, which accelerates to replace coal and oil consumption, then promotes the terminal efficiency sustain rapid ascension[8]. Natural gas consumption grew steadily, but at a slower rate than the conventional transformation scenario. With the rapid development of new energy, the power system has been promoted to a higher level of "source-nets-hold-storage".

\section{Cost Monitoring}

In the future, the cost of power system in China will show the trend of first rise and then decrease. Before 2030, demand growth and transformation development factors are superimposed, and the cost of power system is gradually increasing. Between 2030 and 2050, the growth of electricity demand will be slow, new energy and other technologies will mature, and the cost of power system will gradually decline.

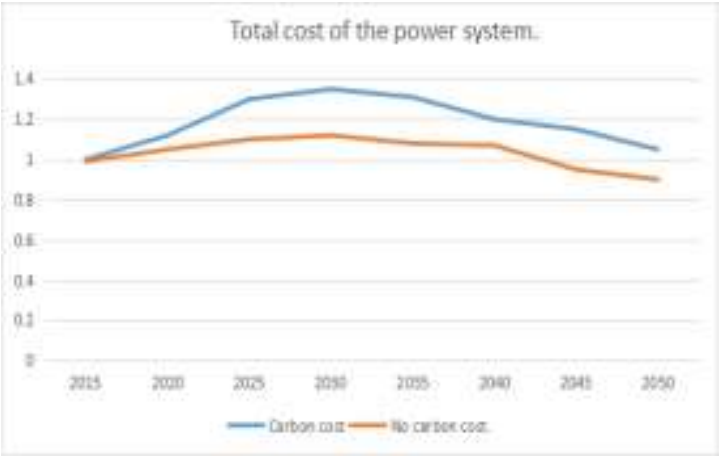

Fig. 2. Total cost of the power system.

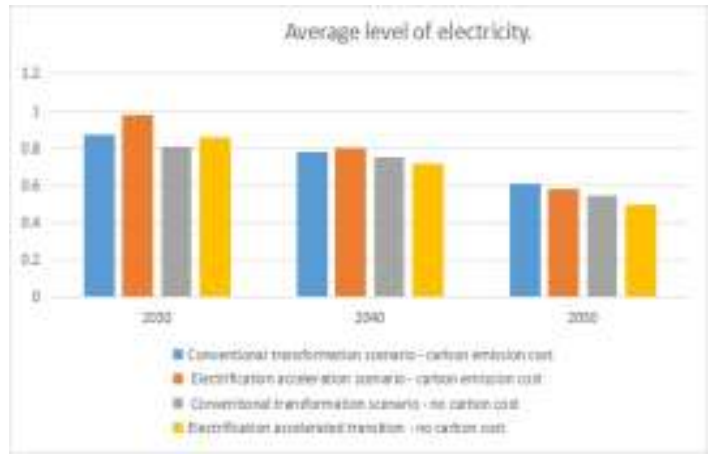

Fig. 3. Average level of electricity.

The peak time for electricity costs is between 2020 and 2030. The medium - and long-term electricity average cost continues to fall, and the decline in electrification acceleration scenario is even greater. In 2050, the cost of electricity will be about half of the current level, and everyone will enjoy high-quality clean energy. 


\section{THE "TwO-STAGE" TASK OF CHINA'S LONG-TERM ENERGY DEVELOPMENT UNDER THE ACCELERATED PATH OF ELECTRIFICATION}

Energy strategy is an important pillar of national development strategy. It will be focused on the two-stage strategic arrangement for the comprehensive construction of a socialist modern country, and plan to transform China's energy medium and long-term development into a two-phase transition task by 2050 :

The modern energy system, which is clean, low-carbon and safe and efficient, has been preliminarily completed, and China has basically realized the socialist modernization. With the rapid development of electrification, the demand of coal and oil has reached a peak, and the non-fossil energy has been developing steadily. The carbon dioxide emission has been reduced and the ecological environment has been improved. The efficiency of energy utilization is increased rapidly, and the total energy consumption is effectively controlled as well.

The clean, low-carbon, safe and efficient energy system has been comprehensively improved, which has effectively supported China's efforts to build a strong, prosperous, democratic, culturally advanced and harmonious modern power. The electrification level is in the advanced ranks of the world, and the energy structure is optimized: the nonfossil energy becomes the leading energy, and the carbon dioxide emissions continue to decline rapidly. Energy efficiency level continues to rise, and the energy consumption reaches peak; the cost of energy supply continues to decrease, and it is a strong impetus for China's energy power to become a clean mode.

\section{CONCLUSION}

Carry out new development concept, in the energy fields to strengthen the green development, the level of electrification on the important indicators of socialist modernization, efforts to promote the development of the electrification strategy rise for the national strategy.

To deepen the supply-side structural reform in the energy sector, we will adhere to the plan and ensure the authority of energy development and power development planning. We will step up coordination between major and regional programs. The key role of power system in energy transformation is to play the role of the power grid in the power system.

We will continue to comprehensively deepen the reform of the energy sector, and gradually break down the institutional mechanisms that affect the development of energy from high speed to high quality. It is necessary to establish perfect new energy given the national unified market ancillary services market, such as carbon trading market mechanism, effectively activate all kinds of market main body, plays a decisive role in the allocation of resources in an all-round way.

With innovation as the first driving force for the transformation and development of the energy industry, a new generation of power systems and other national technology research and development plans are laid out. We will set up a green technology innovation system based on energy enterprises as the main market and the in-depth integration of industry and research, and continuously increase the application of scientific and technological achievements.

\section{REFERENCES}

[1] Giorgio G, Luis F M, Morgan B. An econometric analysis of the effectiveness of development finance for the energy sector. Energy for Sustainable Development. 2014,18(2):16-27.

[2] Tuomo N, Risto K, Juha J. Cost-effectiveness of energy performance renovation measures in Finnish brick apartment buildings. Energy and buildings. 2017,137(2):60-75.

[3] Li Y, Qiu Y M, Wang Y D. Explaining the contract terms of energy performance contracting in China: The importance of effective financing. Energy Economics. 2014,45(9):401-411.

[4] Szabo S, Jaeger W, Szabo F, et al. European renewable government policies versus model predictions. Energy Strategy Reviews. 2014,2(2):257-264.

[5] Romeo P. Implications of applying solar industry best practice resource estimation on project financing. Energy Policy. 2016,95(8):489-497.

[6] Sun X G, Guo L Y, Zeng Z. Market entry barriers for foreign direct investment and private investors: Lessons from China's electricity market. Energy Strategy Reviews. 2013,2(9):169-175.

[7] Konstantinos D, Patlitzianas K C. Effective financing for provision of renewable electricity and water supply on islands. Energy for Sustainable Development. 2012,16(3):120-124.

[8] Ramez A B, Hooi H L, Russell S. Oil curse and finance-growth nexus in Malaysia: The role of investment. Energy Economics. 2016,57(6):154-165. 